\title{
Expression of dendritic cell markers on cultured neutrophils and its modulation by anti-apoptotic and pro-apoptotic compounds
}

\author{
Hae-Young Park ${ }^{1}$, Jun-O Jin ${ }^{1}$, \\ Min-Gyu Song ${ }^{1}$, Joo-In Park ${ }^{1}$ \\ and Jong-Young Kwak ${ }^{1,2}$ \\ ${ }^{1}$ Department of Biochemistry \\ School of Medicine \\ Medical Research Center for Cancer Molecular Therapy \\ Dong-A University \\ Busan 602-714, Korea \\ ${ }^{2}$ Corresponding author: Tel, 82-51-240-2928; \\ Fax, 82-51-241-6940; E-mail, jykwak@ dau.ac.kr
}

Accepted 3 May 2007

Abbreviations: DC, dendritic cell; PDTC, pyrroline dithiocarbamate; $\mathrm{PE}$, phycoerythrin; SEB, staphylococcal enterotoxin

\begin{abstract}
Neutrophils are also known to acquire the characteristics of dendritic cells (DCs) under the appropriate conditions. In this study, neutrophils were cultivated in vitro in the presence or absence of compounds modulating their survival in an attempt to characterize the expression profile of the DC markers. Higher MHC-II, CD80, CD86, CD83, and CD40 expression levels were detected on the surface of the cultured neutrophils for $24 \mathrm{~h}$ than on the freshly isolated cells. The annexin V-positive cells showed a higher expression level of the DC markers than the annexin V-negative cells. The population of neutrophils double stained with annexin $V$ and the $D C$ markers increased after being incubated with agonistic anti-Fas Ab. LPS, the anti-apoptotic compound, decreased the CD86 and MHC-II expression levels but $50-60 \%$ of the DC marker-positive cells were detected in the annexin V-positive cells. In contrast, CD80, CD86, CD83, and HLA-DR mRNA levels increased in the GM-CSF-treated neutrophils but not in the anti-Fas Ab-treated neutrophils. $T$ cell proliferation was inhibited by co-culturing them with anti-Fas Ab- or LPS-treated neutrophils at a high neutrophil:T cell ratio. However, the superantigen-mediated T cell proliferation was increased by the LPS-treated neutrophils but decreased by the anti-Fas Ab-treated neutrophils. There was a lower level of interferon- $\gamma$
\end{abstract}

production in the $\mathrm{T}$ cells co-cultured with anti-Fas Ab-treated neutrophils than with the LPS-treated neutrophils. This suggests that apoptotic neutrophils express DC markers on their surface and the differential expression of DC markers might have a detrimental effect on the immune reaction.

Keywords: antigen-presenting cells; antigens, CD95; apoptosis; dendritic cells; neutrophils

\section{Introduction}

Neutrophils play an important role in the innate immune response by rapidly migrating into inflamed tissues, releasing proteolytic enzymes, and producing reactive oxygen species (Burg and Pillinger, 2001). Neutrophils have also been implicated in modulating the adaptive immune responses. The release of cytokines from neutrophils modulates the $\mathrm{T}$ cell responses, such as chemotaxis and cytokine secretion (Taub et al., 1996). Moreover, it has been demonstrated that neutrophils can function as APCs and induce T cell proliferation in a MHC-Il restricted manner (Radsak et al., 2000). Human peripheral blood and inflammatory neutrophils express functional B7-1-like molecules, and the expression of these molecules is upregulated by the neutrophils of patients with chronic inflammatory disease or Wegener's granulomatosis (Windhagen et al., 1999; lking-Konert et al., 2001b, 2002). The in vitro generation of dendritic cell (DC)-like cells from immediate precursors of mature neutrophils (Oehler et al., 1998) or neutrophils from the peripheral blood using cytokines has also been reported (Yamashiro et al., 2000; lkingKonert et al., 2001a). Neutrophils and immature DCs co-localize during pathogenic challenge (van Gisbergen et al., 2005). Therefore, it appears that neutrophils are capable of up-regulating molecules to present an antigen against naive $T$ cells or can differentiate into DCs through the appropriate stimuli.

Mature neutrophils are terminally differentiated and short-lived cells, and their apoptosis is known to be an important factor in resolving inflammation (Savill, 1997). The apoptotic rate of neutrophils is dependent on the presence of pro- or anti-inflam- 
matory stimuli in the surrounding milieu (Ward et al., 1999b). The spontaneous apoptosis of neutrophils can be enhanced by Fas stimulation (Watson et al., 1997, 1999). Moreover, the onset of apoptosis by neutrophils in vitro is associated with the downregulation of key pro-inflammatory functions, including cell surface receptor expression (Whyte et al., 1993; Dransfield et al., 1994). Moreover, several genes encoding proteins involved in antigen presentation are up-regulated during the initial stages of neutrophil apoptosis (Kobayashi et al., 2003). It has been shown that MHC-II is synthesized by neutrophils after being stimulated with anti-apoptotic cytokines, such as IFN- $\gamma$ or GM-CSF (Fanger et al., 1997; Radsak et al., 2000). In contrast, Mycobacterium tuberculosis infection of neutrophils has been shown to induce CD83 expression on the cells at 3 $\mathrm{h}$ after infection, the time at which early apoptosis was observed, suggesting that neutrophils differentiate into DC-like cells as they start to undergo apoptosis (Aleman et al., 2005). Therefore, the modulation of cell survival can affect the expression of the DC markers on neutrophils. This study investigated whether or not pro- or anti-apoptotic stimuli can modulate the expression of DC markers on neutrophils.

\section{Materials and Methods}

\section{Reagents}

Histopaque, propidium iodide (PI), LPS, pyrroline dithiocarbamate (PDTC), staphylococcal enterotoxin B (SEB), and brefeldin A were purchased from Sigma (St. Louis, MO). The Giemsa staining solution was purchased from Fluka (Bushes, Switzerland). The dextran was obtained from Amersham Pharmacia Biotech (Uppsala, Sweden). The GM-CSF was acquired from R\&D Systems Inc. (Minneapolis, MN). The RPMI-1640 medium was supplied by Gibco-BRL (Rockville, MD). The RT-PCR kit was obtained from Promega (Madison, $\mathrm{WI}$ ). The FITC or phycoerythrin (PE)-conjugated anti-CD80, CD83, CD86, CD40, MHC-II, HLA-DR, CD16, CD32, CD3 and isotype control Abs (lgG1, IgG2a) were purchased from BD Pharmingen (Flanklin lakes, NJ). The anti-caspase-3 Ab was acquired from Santa Cruz Biotech (Santa Cruz, CA).

\section{Cell culture}

The peripheral blood neutrophils were isolated from healthy young donors using a method involving dextran sedimentation and differential centrifugation through a Ficoll-Hypaque density gradient
(Park et al., 2002). The donors were confirmed not to have taken any anti-inflammatory drugs for at least three weeks before sampling. Informed consent was obtained from all participants and the local institutional review board at Dong-A University Hospital approved the study. The neutrophils were shown to be $98 \%$ pure by microscopy. The contaminating monocytes were depleted using anti-CD14 Ab-coated magnetic beads (Milteny Biotec Inc., Auburn, CA). The detection of CD14 ${ }^{+}$ cells in the separated neutrophils was $<0.1 \%$ in flow cytometry analysis using FITC-conjugated anti$\mathrm{CD} 14 \mathrm{Ab}$. The isolated neutrophils $\left(1 \times 10^{5} / 100 \mu \mathrm{l}\right)$ were maintained in RPMI 1640 medium supplemented with $5 \%$ FBS, $1 \%$ glutamine, $100 \mathrm{U} / \mathrm{ml}$ penicillin, and $100 \mu \mathrm{g} / \mathrm{ml}$ streptomycin in 96-well flat bottomed plates at $37^{\circ} \mathrm{C}$ in a humidified atmosphere containing $5 \% \mathrm{CO}_{2}$.

\section{Morphological assessment of neutrophil apoptosis}

The neutrophils incubated in the presence or absence of anti-Fas $A b$, or various agents were spun down on a glass slide using a cytospin (Shandon, Pittsburgh, PA). The cells were fixed with methanol and stained with the Giemsa staining solution. Typical apoptotic cells were readily identified by the nuclear condensation and cytoplasmic vacuoles.

\section{Flow cytometric analysis}

The level of phosphatidylserine exposure was determined by measuring the extent of annexin V-FITC binding using an apoptosis detection kit (Oncogene Research Product). The cells $\left(1 \times 10^{6}\right)$ were first harvested and washed with PBS. The cells were incubated with $\lg G$ of the same isotype at $4^{\circ} \mathrm{C}$ for $1 \mathrm{~h}$ to block nonspecific staining or FC receptor-mediated binding of $A b$. They were then labeled with FITC- or PE-conjugated Abs, incubated on ice for $30 \mathrm{~min}$ and washed with an isotonic PBS buffer supplemented with 0.5\% BSA. The cells $\left(1 \times 10^{4}\right)$ were subsequently analyzed by flow cytometry (Beckton Dickinson, Franklin Lakes, NJ) (Park et al., 2005). Isotype-matched irrelevant $A b$ was used as a control for nonspecific staining and fluorescence parameters were gated using stained cells with FITC- or PE-conjugated isotype $\mathrm{Ab}$.

\section{RT-PCR analysis}

The total RNA from CD14 $\mathrm{CD}^{-} 6 \mathrm{~b}^{+}$cells $\left(1 \times 10^{6}\right)$ was isolated and lysed with TRIZOL reagents (Invitrogen). Each $50 \mu \mathrm{l}$ PCR reaction mixture contained 
$1.5 \mathrm{U}$ DNA polymerase, $200 \mu \mathrm{M}$ dNTP, $50 \mathrm{pmol}$ of the oligonucleotide primers. The reaction was amplified in a DNA thermal cycler for 30 cycles using the following PCR program: $95^{\circ} \mathrm{C} 1 \mathrm{~min}, 55^{\circ} \mathrm{C} 1$ $\min , 72^{\circ} \mathrm{C} 30 \mathrm{~s}$. Two specific primers were used; $\beta$ actin, ATGGATGATGATATCGCCGCG (sense), TCTCCATGTCGTCCCAGTTG (antisense), (249 bp); CD80, TTGGATTGTCATCAGCCCTGC (sense), ATTTTCTTCTCCTTTTGCCAGTAG (antisense) (318 bp); CD83, GCCATGTCGCGCGGCCTCCAGCTT (sense), GGACAATCTCCGCTCTGTATTTC (antisense), (440 bp); CD86, AGGACAAGGGCTTGTATCAA (sense), ATTGCTCGTAACATCAGGGA (antisense), (330 bp); HLA-DR, CGGATCCTTCGTGTCCCCAC (sense), CTCCCCAACCCCGTAGTTGTGTCTGCA (antisense), (270 bp).

\section{Western blot analysis}

The cell extracts from the freshly isolated or cultured neutrophils were subjected to SDS-PAGE and transferred to nitrocellulose membranes. The membranes were incubated overnight at $4^{\circ} \mathrm{C}$ with the primary Abs in a blocking buffer, followed by incubation with the secondary Abs for $1 \mathrm{~h}$ at $25^{\circ} \mathrm{C}$. The signals were detected using an ECL chemiluminescence kit.

\section{T cell proliferation assay}

The $T$ cells were harvested from the mononuclear fraction of the peripheral blood and further purified using anti-CD3 Ab-coated magnetic beads. The purity was determined by staining the cells with FITC-conjugated anti-CD3 Ab and was $>98 \%$. The neutrophils which had been cultured for $24 \mathrm{~h}$ with or without LPS $(100 \mathrm{ng} / \mathrm{ml}), \mathrm{GM}-\mathrm{CSF}(10 \mathrm{ng} / \mathrm{ml})$, or anti-Fas $A b(1 \mu \mathrm{g} / \mathrm{ml})$ were harvested, washed with the culture medium, and added to $1 \times 10^{5} \mathrm{~T}$ cells in 96-well culture plates. The mixture was cultured for $24 \mathrm{~h}$ at $37^{\circ} \mathrm{C}$ in $5 \% \mathrm{CO}_{2}$ in the presence of SEB $(100 \mathrm{ng} / \mathrm{ml})$ and pulsed for $18 \mathrm{~h}$ with $1 \mu \mathrm{Ci}\left[{ }^{3} \mathrm{H}\right]$ thymidine (NEN-DuPont, Boston, MA). The T cells were cultured without neutrophils as a reference. The cells were harvested and the levels of radioactivity incorporated were determined using a scintillation counter.

\section{Cytokine assay}

The IFN- $\gamma$ levels in the culture supernatant were quantified using a ELISA kit (R\&D Systems). The analyses were carried out according to the manufacturer's instructions.

\section{Statistical analysis}

The results are presented as a mean $\pm S D$. A Student's $t$-test was used to compare the means of the unpaired samples. A $P$ value $<0.05$ was considered significant.

\section{Results}

\section{Detection of DC markers on neutrophils in culture condition}

The expression levels of the co-stimulatory molecules (CD80 and CD86), CD40, CD83, and MHC-II by the cultured neutrophils were analyzed using immunofluorescent flow cytometry. As shown in Figure $1 \mathrm{~A}$, the number of cells stained positively to each marker increased when the neutrophils were cultured for $24 \mathrm{~h}$ in a simple medium containing $5 \%$ FBS. The percentages of $\mathrm{CD}^{+} 0^{+}, \mathrm{CD}^{+} 6^{+}$, $\mathrm{CD} 3^{+}, \mathrm{MHC}^{-\mathrm{II}^{+}}$, and $\mathrm{CD}_{40}^{+}$expressing neutrophils after $24 \mathrm{~h}$ culture were $20 \pm 4 \%, 62 \pm 8 \%$, $12 \pm 6 \%, 60 \pm 5 \%$, and $6 \pm 3 \%$, respectively (Figure $1 \mathrm{~A}$ and 1B). Time course analysis showed that the expression of each molecule on the neutrophil surface increased in a time dependent manner (Figure 1B). The percentage of $\mathrm{CD}^{+} 6^{+}$ cells increased significantly after $12 \mathrm{~h}$. There was no further increase in the surface expression of these molecules after culturing for an additional 24 h (data not shown). Moreover, the percentage of CD83-positive cells, which might be a specific surface marker of DC maturation, was higher in the cultured neutrophils than in the freshly isolated cells. Next, double staining was performed using FITC-conjugated anti-CD66b $\mathrm{Ab}$ and PE-conjugated anti-CD80 $\mathrm{Ab}$ in order to exclude contamination by $\mathrm{CD} 14^{+}$monocytes or other APCs because $C D 66 \mathrm{~b}$ is a marker for the neutrophils. As shown in Figure $1 \mathrm{C}$, more than $98 \%$ of the freshly isolated cells were CD66b positive, and CD66b expression level did not change in the cultured cells. More than $15 \%$ of the cultured cells tested were positive for both CD66b and CD80.

\section{The expression level of DC markers on apoptotic neutrophils}

The markers characteristic of DCs were up-regulated in the neutrophils cultured for $24 \mathrm{~h}$ in vitro but the cultured neutrophils contained a similar number of apoptotic and aged cells. Therefore, this study investigated which cells up-regulated the DC markers on their surface after culturing for $24 \mathrm{~h}$. The level of cell survival was assessed by the morphological changes and flow cytometric analysis 
A

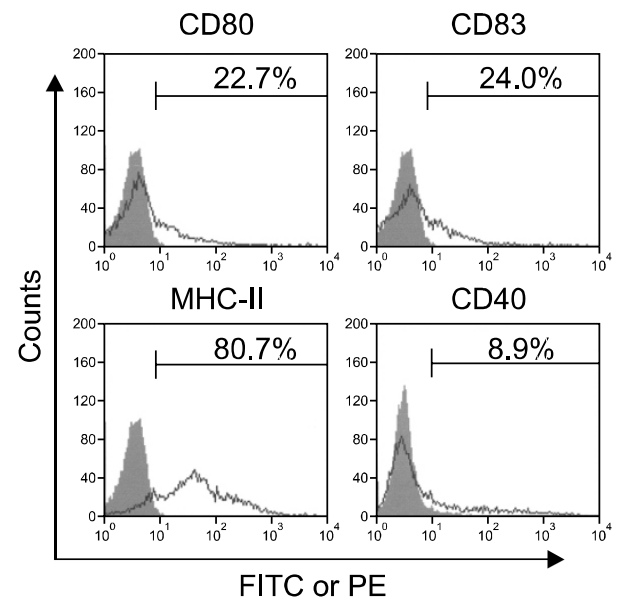

B

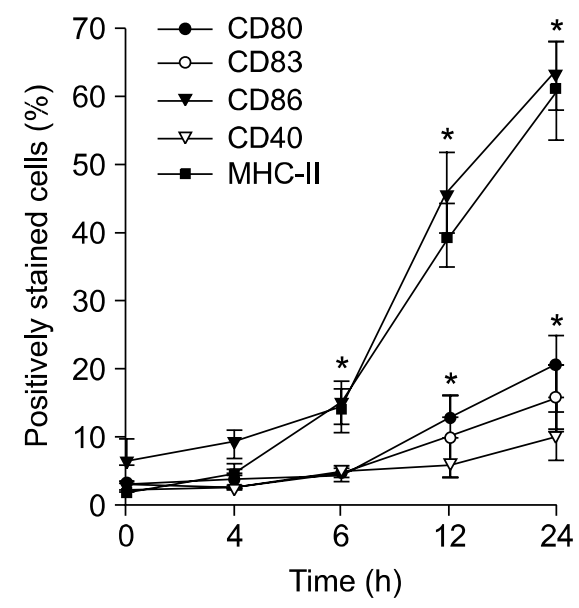

C

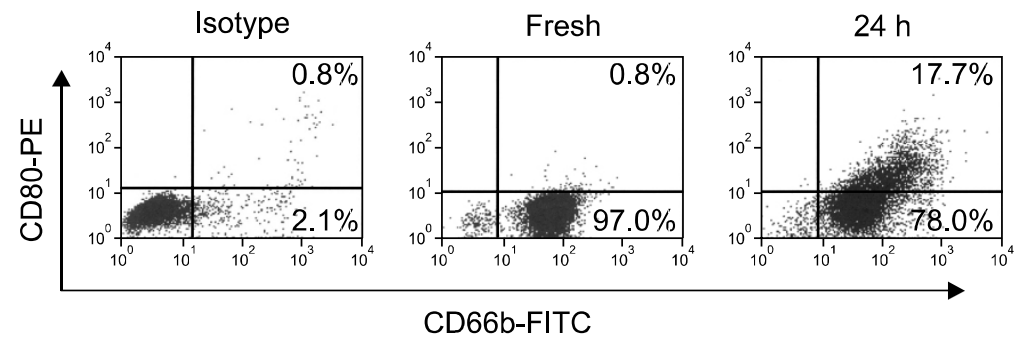

Figure 1. The expression of $\mathrm{CD} 80, \mathrm{CD} 86, \mathrm{CD} 83, \mathrm{MHC}-\mathrm{II}$, and $\mathrm{CD} 40$ on in vitro cultured neutrophils. (A) Neutrophils $\left(1 \times 10^{6}\right)$ were isolated, cultured for $24 \mathrm{~h}$, harvested, and preincubated with isotype-matched control Abs. FITC-conjugated Abs were then used to detect CD80, CD83, MHC-II, and CD40, as described in "Materials and Methods". Fluorescence parameter was gated using FITC-conjugated isotype control Ab and the gray areas in the plots indicate the isotype controls. The results are representative of three independent experiments. (B) Neutrophils were incubated for the indicated times and harvested. The cells were preincubated with isotype-matched lgG for $1 \mathrm{~h}$ and then stained with FITC-conjugated Abs. Their expression levels were analyzed using flow cytometry. The results are shown as a mean $\pm S D$ of positively stained cells from three independent experiments. (C) Freshly isolated or 24 h-cultured neutrophils were stained with anti-CD66b Ab-FITC and anti-CD80 Ab-PE as described in "Materials and Methods". The results are representative of three independent experiments. The numbers indicate the percentage of positively stained cells. ${ }^{*} P<0.05 \mathrm{vs}$. freshly isolated cells.

of $\mathrm{PI}$ staining and annexin $\mathrm{V}$ binding. The neutrophils rapidly underwent spontaneous apoptosis in the in vitro culture. More than $50-60 \%$ of the cells were annexin V-positive and had a typical apoptotic cell morphology after $24 \mathrm{~h}$ of culture (Lee et al., 2004). The cells were then double stained for the PE-conjugated DC markers and annexin V-FITC. As shown in Figure 2A, the majority of the DC marker-positive cells also were positive to annexin V-FITC. Treating the neutrophils with agonistic anti-Fas $A b$ for $24 \mathrm{~h}$ significantly increased both the rate of apoptosis and the percentage of DC makers-positive cells, although the population of $\mathrm{CD} 83^{+}$and annexin $\mathrm{V}^{+}$did not significantly increase. This suggests that apoptotic neutrophils express DC markers on their cell surface under the culture conditions examined.
The relationship between the expression level of Fc $\gamma$ receptor $(F c \gamma R)$ and $D C$ markers was next investigated. The CD16 (FcyRIII) expression level decreased in neutrophils cultured for $24 \mathrm{~h}$ (Figure 2B) (Dransfield et al., 1994). GM-CSF restored the CD16 expression level but Fas stimulation decreased its level. However, the CD32 (FcyRII) expression level was not changed under any of the culture conditions examined. The CD80-positive cells were mainly detected in the CD16-negative cells and CD32-positive cells, and Fas stimulation increased the population of $\mathrm{CD}^{-} 6^{-} \mathrm{CD} 80^{+}$cells or $\mathrm{CD} 32^{+} \mathrm{CD} 80^{-}$cells. Moreover, a $24 \mathrm{~h}$ treatment with GM-CSF decreased the CD80 expression level on neutrophils compared with the cells cultured with the media alone, even though GM-CSF-treated neutrophils expressed a higher level of CD80 than 
A

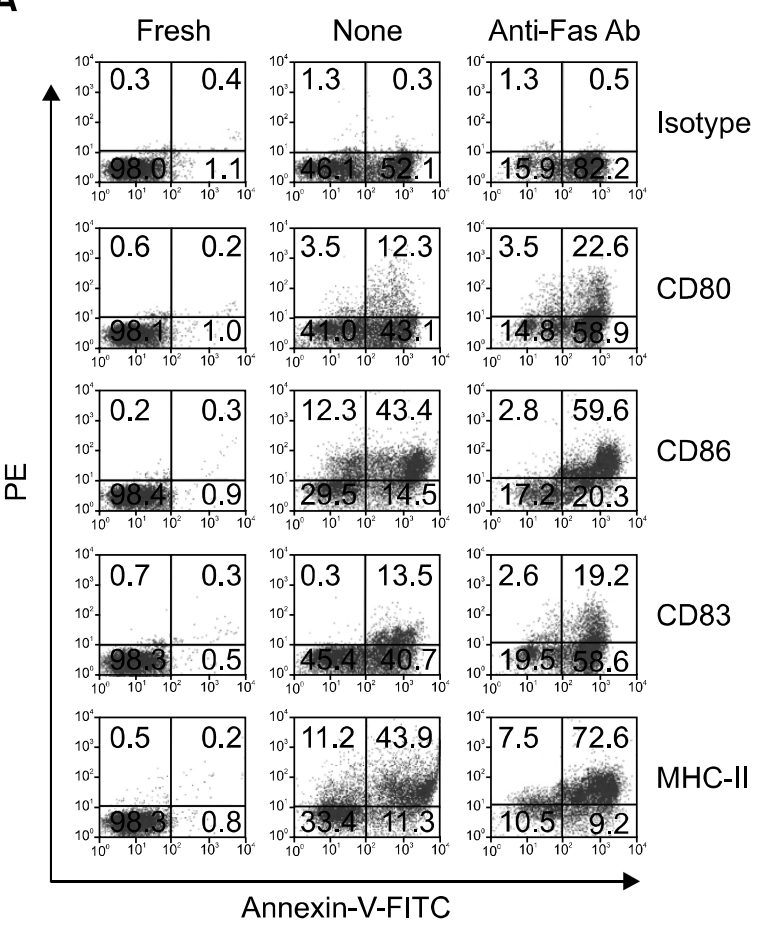

C

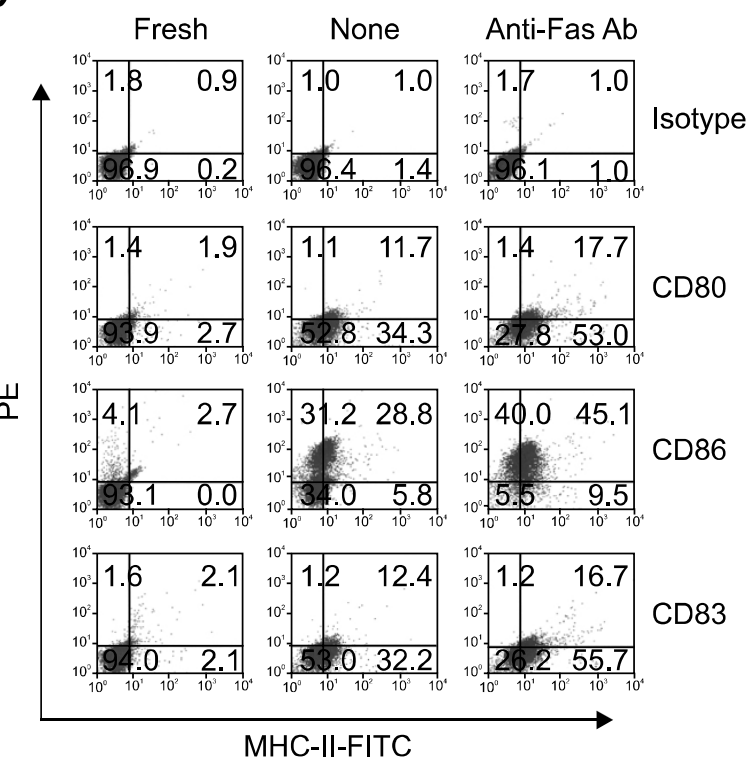

B

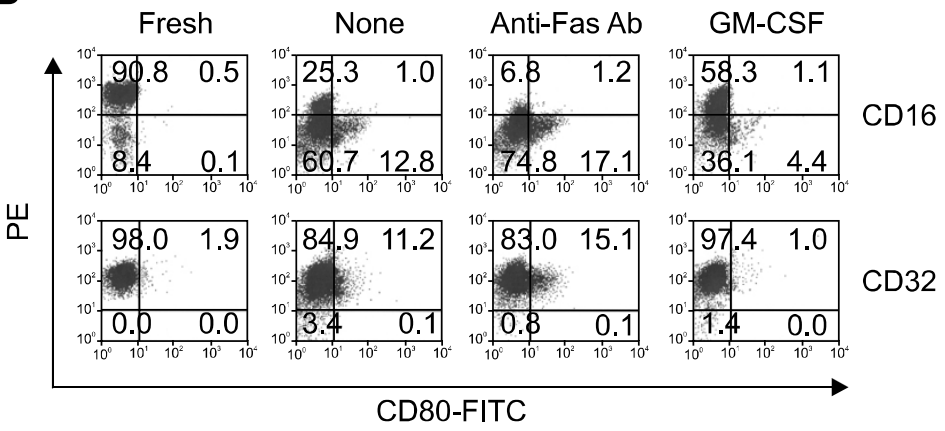

Figure 2. The expression of DC markers on apoptotic neutrophils. (A) Neutrophils were incubated with or without $1 \mu \mathrm{g} / \mathrm{ml}$ anti-Fas Ab for $24 \mathrm{~h}$. The cells were harvested, preincubated with control lgG for $1 \mathrm{~h}$, and double-stained with PE-conjugated Abs and annexin V-FITC. (B) Neutrophils were incubated with or without anti-Fas Ab or $10 \mathrm{ng} / \mathrm{ml}$ GM-CSF for $24 \mathrm{~h}$. The cells were harvested, preincubated with control lgG for $1 \mathrm{~h}$, and double-stained with PE-conjugated anti-CD16 or anti-CD32 Ab and FITC-conjugated anti-CD80 Ab. (C) Cells were treated as in panel A and doubly stained with FITC-conjugated anti-MHC-II Ab and PE-conjugated anti-CD80, anti-CD83, or anti-CD86 Ab. Fluorescence parameter was gated using FITC- and PE-conjugated isotype control Abs (Isotype). The results are representative of three independent experiments.

the freshly isolated neutrophils. The population of CD $16{ }^{-}$CD $80^{+}$cells was also decreased by the GMCSF treatment. Markers of costimulatory molecules appeared in variable percentages of the apoptotic cells together with high levels of expression of MHC-II. Thus, a double immuno-staining was performed next by using FITC-conjugated anti-MHC-II Abs and PE-conjugated anti-CD80, anti-CD86, or anti-CD83 $A b$ to possibly identify whether there was a correlation between expression levels of MHC-II and expression levels of costimulatory molecules on apoptotic neutrophils. As shown in Figure 2C, the percentage of populations of $\mathrm{CD}^{-} \mathrm{MHC}-\mathrm{II}^{+}$ was higher than those of $\mathrm{CD}^{+} 0^{+} \mathrm{MHC}-\mathrm{II}^{+}(53.3 \pm$ $8.5 \%$ vs $18.9 \pm 4.5 \%, P<0.001)$. However, CD86 expression was mainly found to be in the MHC$\mathrm{II}^{+}$-population. The CD83-positive cells were mainly detected in the MHC-II-positive cells (17.5 $\pm 2.7 \%$ vs $1.2 \pm 0.5 \%, P<0.01)$. These findings indicate that DC markers are differentially expressed on the apoptotic neutrophils. 


\section{mRNA and protein expression levels of DC markers in cultured neutrophils}

The mRNA expression levels of the various DC markers were measured after 2, 4, 6, 12, and $24 \mathrm{~h}$ culture with or without GM-CSF or anti-Fas $A b$ (Figure 3A). The HLA-DR mRNA expression level of cultured neutrophils with media alone increased after $2 \mathrm{~h}$ culture and decreased thereafter. However, the presence of GM-CSF caused the HLA-DR mRNA expression level to increase for up to $24 \mathrm{~h}$, whereas anti-Fas $A b$ failed to increase the HLADR mRNA level. The CD80 and CD86 mRNA levels were not dramatically changed at the early time points but were increased in the presence of GM-CSF after $24 \mathrm{~h}$. CD83 mRNA was up-regulated after $2 \mathrm{~h}$ culture with the media alone and was decreased after prolonged incubation. The reduction of CD83 mRNA level was attenuated by GMCSF but not by anti-Fas Ab. However, there was no correlation between the alterations in the CD80, CD86, CD83, and HLA-DR mRNA levels and the changes in cell surface expression detected by flow cytometry. Therefore, surface expression appears to be the result of translational or posttranslational events.

The intracellular protein levels of DC markers in cultured neutrophils were measured by Western blotting using commercially available Abs. As shown in Figure $3 \mathrm{~B}$, the intracellular proteins of CD80 and CD86 in the freshly isolated neutrophils were not detected but their levels increased after culturing for $24 \mathrm{~h}$. The total HLA-DR protein level in the neutrophils cultured for $24 \mathrm{~h}$ was similar to that in the freshly isolated neutrophils. GM-CSF increased the HLA-DR protein level in the neutrophils cultured for $24 \mathrm{~h}$ but did not affect the CD80 and CD86 protein levels. When the neutrophils were stimulated with anti-Fas $A b$, there was a slight increase in the level of HLA-DR proteins but the CD80 and CD86 protein levels were relatively unchanged.

\section{Effect of pro-apoptotic compounds on the expression of DC markers}

It has been shown that brefeldin $A$, an inhibitor of the vesicle transport event, and PDTC, an NF-kB inhibitor, induce the apoptosis of neutrophils (Ward et al., 1999a; Lee et al., 2003). These pro-apoptotic compounds increased the rate of apoptosis by up to $90 \%$ after $24 \mathrm{~h}$ culture (Lee et al., 2004). The CD80, CD83, and CD86 levels were higher in the neutrophils treated with brefeldin A or PDTC than in the neutrophils cultured with media alone (Figure 4). Moreover, CD80, CD83, and CD86 were expressed exclusively on the annexin V-positive cells.
A
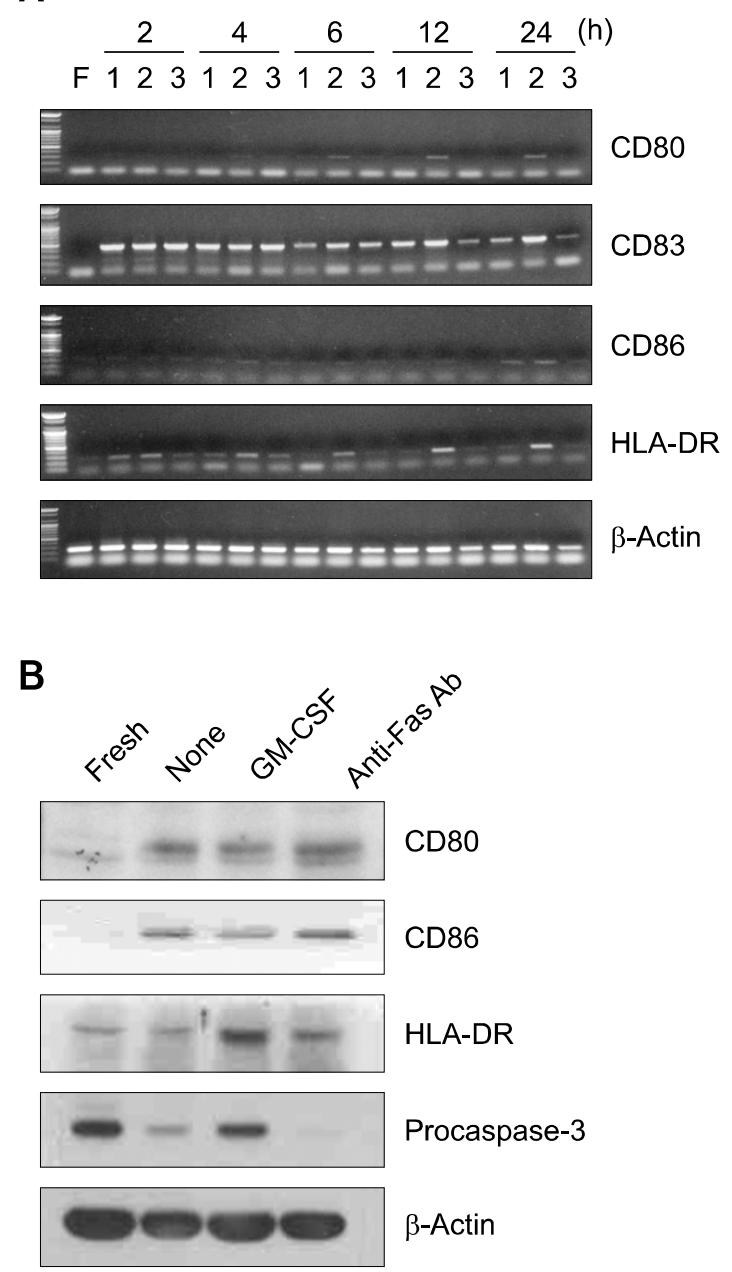

Figure 3. The expression levels of $m R N A$ and proteins of $D C$ markers in cultured neutrophils. $(A) C D 14^{-} C D 66 b^{+}$cells $\left(1 \times 10^{6}\right)$ were cultured for the indicated times with or without GM-CSF (lane 2) or anti-Fas Ab (lane 3). Lane 1 represents the neutrophils cultured with media alone. mRNA purification and RT-PCR were performed as described in "Materials and Methods". mRNA expression of $\beta$-actin was used as a control. (B) The cell lysates were prepared and subjected to SDS-PAGE and immunoblotting using anti-CD80, CD86, HLA-DR, procaspase-3, and $\beta$-actin Abs. As a positive control, the amount of procaspase-3 proteins in the lysates of cultured neutrophils was measured. A representative of three separate experiments from three donors is shown.

However, the MHC-II level increased slightly in the presence of pro-apoptotic compounds after culturing for $24 \mathrm{~h}$ compared with the media alone and most of the MHC-II-positive cells were detected in the annexin V-positive population. The neutrophils incubated with LPS, another anti-apoptotic agent for neutrophils, showed a significant delay in the rate of spontaneous apoptosis. After $24 \mathrm{~h}$ in the presence of LPS, only $20-30 \%$ of cells were apoptotic. The CD80-, CD83-, CD86-, or MHC-II-positive cells made up $<10 \%$ of the total number of neutrophils but $50-60 \%$ of the DC marker-positive cells in the 

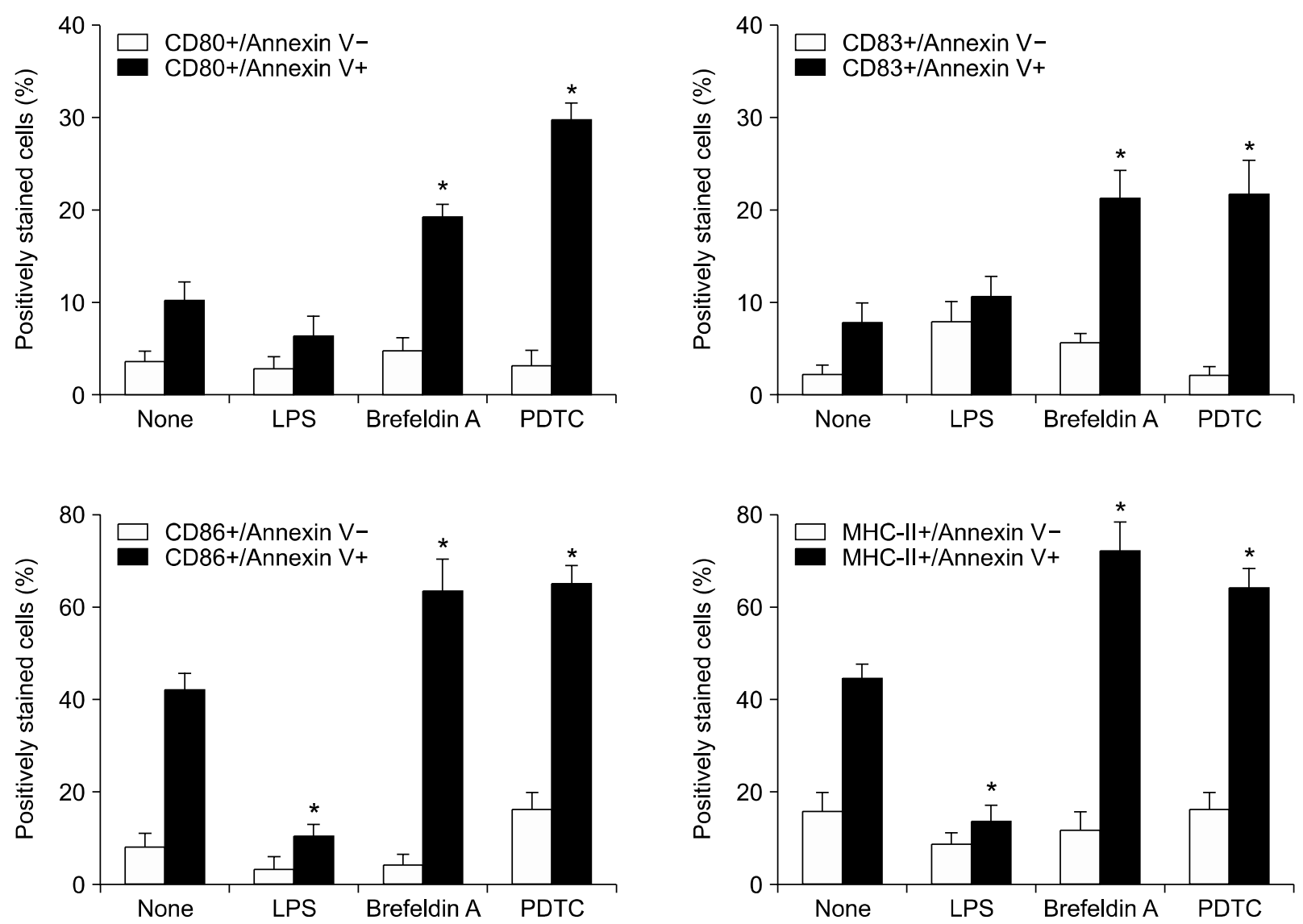

Figure 4. Increased expression of DC markers on neutrophils by pro-apoptotic compounds. Neutrophils were cultured in the presence of LPS (100 ng/ml), brefeldin A $(10 \mu \mathrm{M})$, or PDTC $(10 \mu \mathrm{M})$ for $24 \mathrm{~h}$. The cells were harvested, preincubated with control lgG for $1 \mathrm{~h}$, and stained with annexin V-FITC and PE-conjugated anti-CD80, CD83, CD86, or MHC-II Abs, as described in Figure 2. The mean \pm SD of annexin V-positive or -negative cells among DC markers-stained cells is presented from three independent experiments. ${ }^{*} P<0.05$ vs. None.

LPS-treated neutrophils were annexin V-positive.

\section{Effect of cultured neutrophils on T cell activation}

The ability to stimulate $T$ cells is one of the key functions of DCs. Therefore, this study examined the amount of IFN- $\gamma$ secreted from the mixed culture of $T$ cells and neutrophils which had been cultured with the medium alone, LPS, GM-CSF, or anti-Fas Ab. When the anti-Fas Ab or LPS-pretreated neutrophils were harvested, washed, and co-cultured with T cells for $24 \mathrm{~h}$, the levels of IFN- $\gamma$ secreted in the culture media containing Fasstimulated neutrophils was lower than containing the LPS-treated neutrophils. However, the level of IFN- $\gamma$ secretion under both conditions increased significantly at a 10:1 ratio of neutrophils (Figure $5 \mathrm{~A})$. It has been shown that $\mathrm{MHC}$-II-expressing neutrophils induce superantigen-mediated $\mathrm{T}$ cell activation (Fanger et al., 1997). When neutrophils, which had been treated with or without GM-CSF,
LPS, or anti-Fas Ab, were co-cultured with the $T$ cells for $24 \mathrm{~h}$ in the presence of SEB, the magnitude of the response of $T$ cells to SEB was proportional to the number of cultured neutrophils. However, more IFN- $\gamma$ secretion was observed with the GM-CSF-treated neutrophils at a ratio of approximately $1: 10$ than that observed with the Fasstimulated neutrophils (Figure 5B). Next, we examined the $\mathrm{T}$ cell proliferation in the co-cultured condition with neutrophils for $24 \mathrm{~h}$ in the presence of SEB because $50-60 \%$ of the neutrophils were already apoptotic at $24 \mathrm{~h}$ of culture. As shown in Figure 6 , SEB alone stimulated the proliferation of $T$ cells but the addition of LPS- or anti-Fas Abtreated neutrophils did not enhance the level of $T$ cell proliferation at low neutrophil:T cell ratios. On the other hand, $\mathrm{T}$ cell proliferation was further stimulated by LPS-treated neutrophils at a neutrophil: $T$ cell ratio of $10: 1$ in the presence of SEB but inhibited by anti-Fas Ab-treated neutrophils. This suggests that apoptotic neutrophils expre- 
A

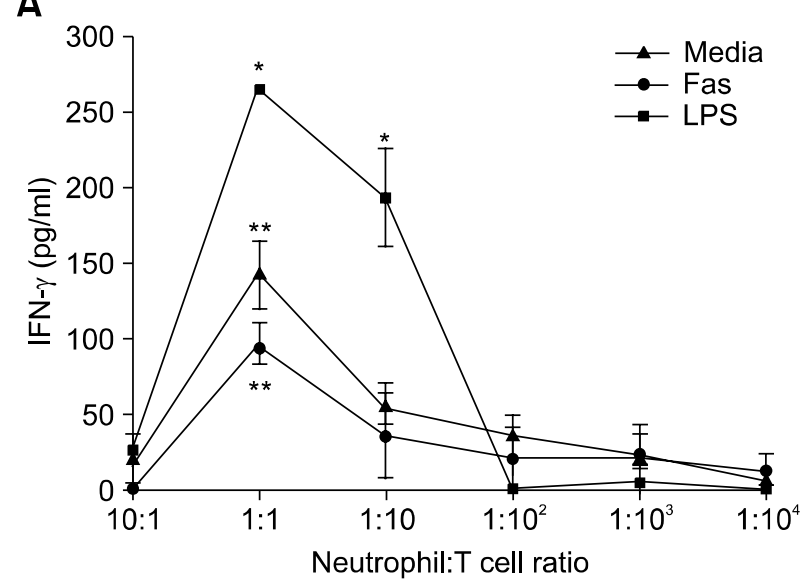

B

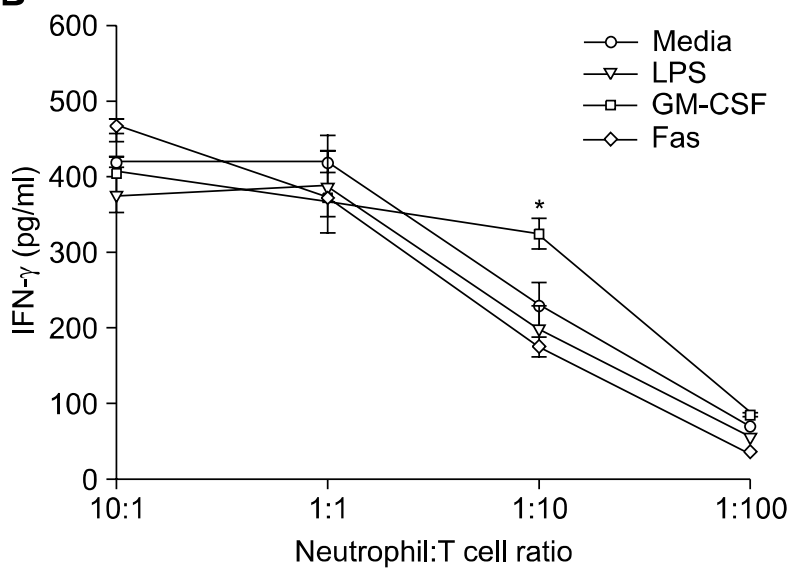

Figure 5. IFN- $\gamma$ production by T cells co-cultured with anti-Fas Ab-, GM-CSF-, or LPS-treated neutrophils. CD14 CD66b ${ }^{+}$cells $\left(1 \times 10^{6} / \mathrm{ml}\right)$ were cultured with or without GM-CSF, LPS, or anti-Fas Ab for $24 \mathrm{~h}$, harvested, and washed with medium twice. The cells were then mixed with $\mathrm{T}$ cells $\left(1 \times 10^{5}\right)$ in the indicated ratios and cultured for $24 \mathrm{~h}$ in the absence (A) or presence (B) of SEB (100 ng/ml). The culture media were withdrawn and the IFN- $\gamma$ concentrations were measured by ELISA. The results are presented as the mean \pm SD of a triplicate assay from two separate cultures. ${ }^{*} P<0.001$ vs. anti-Fas Ab-treated neutrophils, ${ }^{* *} P<0.05$ vs. T cell alone.

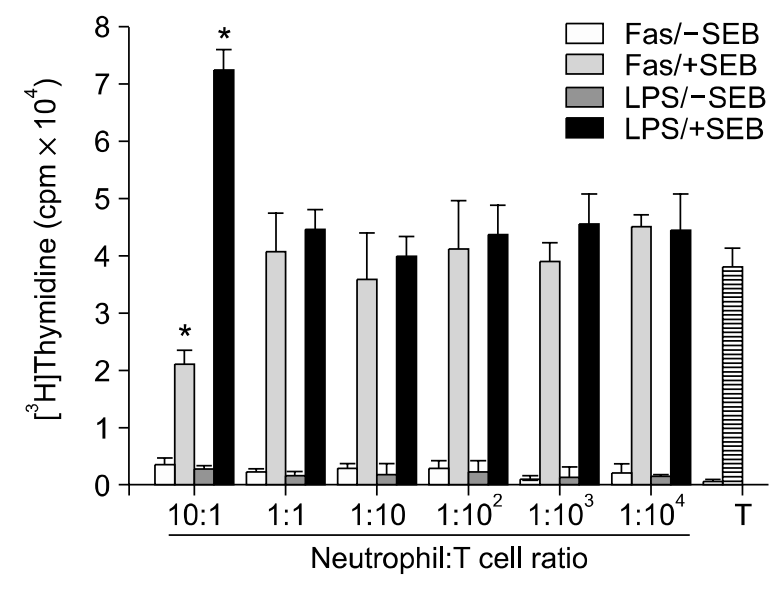

Figure 6. T cell proliferation in co-cultured condition with anti-Fas Ab- or LPS-treated neutrophils. CD14 ${ }^{-} \mathrm{CD} 6 \mathrm{~b}^{+}$cells were separated and treated as shown in Figure 5 . The cells were then harvested and washed twice with the media. These cells were mixed with the indicated ratio of $T$ cells for $24 \mathrm{~h}$ in the presence of SEB $(100 \mathrm{ng} / \mathrm{ml})$. The mixed cells were further cultured for $18 \mathrm{~h}$ after adding $1 \mu \mathrm{Ci}\left[{ }^{3} \mathrm{H}\right]$ thymidine. T cells stimulated with SEB were used as the positive control, and T cells cultured alone were used as the negative control. The incorporation of $\left[^{3} \mathrm{H}\right]$ thymidine was determined using a scintillation counter. The results are presented as a mean \pm SD of triplicate cultures. ${ }^{*} P<0.05$ vs. T cell alone.

ssing DC markers on their surfaces have no stimulatory activity on T cells.

\section{Discussion}

Recent experimental data suggests that neutrophils have the potential to trans-differentiate into
DCs (Oehler et al., 1998; Yamashiro et al., 2000; Iking-Konert et al., 2001a). Therefore, neutrophils appear to have different phenotypic characteristics depending on a variety of factors, including the survival duration. This study showed that the number of neutrophils expressing MHC-II, co-stimulatory molecules, and CD83 was increased by culturing neutrophils for $24 \mathrm{~h}$ without any cytokines. This suggests that these neutrophils acquired the DC phenotype. Almost all annexin V-positive cells expressed MHC-II, whereas only a portion of annexin V-positive cells expressed other DC markers. Thus, the expression of all DC markers was not regulated in a similar fashion. It is unclear whether cells expressing DC markers go into apoptosis or cells that become apoptotic express DC markers. It has been shown that the increased apoptotic signals delivered by recombinant FasL induce CD80 expression (de Carvalho Bittencourt et al., 2002) and that the sodium butyrate-induced CD86 expression is related to the apoptosis of HL-60 cells (Suzuki et al., 2003). Another group has also reported that monocytes differentiate into DCs without the addition of exogenous cytokines in an in vitro model of trans-endothelial migration (Randolph et al., 1998). The possibility that the increased detection of DC markers on the surface of neutrophils may be due to contaminating monocytes and lymphocytes can be ruled out for the following reasons: (1) the freshly isolated neutrophils tested were negative for the CD14 marker, (2) the proportion of DC maker-positive cells was too high to be derived from monocytes or lymphocytes after purification, (3) all the DC markers were 
detected on the CD14 and $\mathrm{CD}^{-} 6 \mathrm{~b}^{+}$cells. Furthermore, the possibility of the nonspecific binding of Abs to the cell surfaces can be also ruled out by the differential expression of the DC markers on the apoptotic or aged cells. In addition, our data indicate that the CD16 expression level decreased in neutrophils cultured for $24 \mathrm{~h}$ and the CD80positive cells were mainly detected in the CD16negative cells. Moreover, the apparent DC marker detection could be the consequence of the poor fluorescence compensation or, alternatively, of an analysis that included cell debris or necrotic cells which are known to non-specifically bind antibodies. In this regard, we included the related plot showing isotype controls after fluorescence compensation.

The CD80 and CD86 proteins were not expressed in the freshly isolated neutrophils but their intracellular protein levels were higher in the cultured neutrophils for $24 \mathrm{~h}$. The CD83 and HLA-DR mRNA expression levels were increased in the neutrophils after $2 \mathrm{~h}$ culture with media alone. The GM-CSF treatment increased the mRNA expression level of the DC markers, including CD80 and CD86. However, there was increased expression of the surface DC markers on the neutrophils cultured with anti-Fas Ab but their mRNA expression levels were not changed by anti-Fas $A b$. Other group has also shown that HLA-DR surface expression on neutrophils is induced by the cell surface interactions of neutrophils with the cell lines of the lymphoid phenotype and is not altered by the cycloheximide treatment (Vella et al., 2002). This indicates that the phenomenon is independent of the de novo gene activation and protein synthesis (Vella et al., 2002). NF-kB might be the main transcriptional activator involved in inducing CD80 and CD86 gene expression (Zhao et al., 1996; Yoshimura et al., 2001), and it is also known to be an anti-apoptotic activator (Ward et al., 1999a). However, NF-kB inhibitor did not attenuate the expression of CD80 and CD86, rather their expression level on the apoptotic neutrophils was increased. Overall, the surface expression of CD80, CD83, CD86, and MHC-II might occur via the translocation of the molecules from the cytosolic fraction or post-transcriptional events. It is possible that the surface DC markers on the apoptotic neutrophils may be transient but not inducible like anionic phosphatidylserine, which is relocated to the outer surface of the plasma membrane during apoptosis.

It has been suggested that the temporally regulated expression of the co-stimulatory molecule might initiate T cell-dependent immunity (Sethna et al., 1994). Among the many co-stimulatory signals, members of the B7 family on the APCs interact with CD28 and the cytotoxic T lymphocyte antigen-4 on T cells. CD80 and CD86 are involved in the Th1 and Th2 responses, respectively (Kuchroo et al., 1995). It was reported that neutrophils promote the Th1 responses in experimental models of infection with Legionella pneumophillia or Toxoplasma gondii (Bliss et al., 2000; Tateda et al., 2001). However, it is still unclear if $\mathrm{T}$ cells can interact with neutrophils that express $\mathrm{MHC}$ and co-stimulatory molecules. Mencacci et al. (2002) reported that $\mathrm{Gr}-1^{+}$neutrophils inhibit the activation of IFN- $\gamma$-producing $\mathrm{CD}^{+}$ $T$ cells and induce apoptosis through a CD80/ CD28-dependent mechanism. They suggested that alternatively activated neutrophils expressing CD80 might adversely affect the Th1-dependent resistance in fungal infections. This study showed that CD80 and CD86 were also detected on the cultured neutrophils and further elevated in the apoptotic cell population. This suggests that apoptotic neutrophils might have more ability to interact with $\mathrm{T}$ cell receptors than aged cells. However, there was no correlation between the production of cytokines or T cell activation and the expression level of DC markers on the cultured neutrophils. On the contrary, LPS-treated neutrophils expressed a lower level of MHC-II but induced higher $\mathrm{T}$ cell activation and proliferation as compared with apoptotic neutrophils. Apoptotic cells become positive for PI staining in the later phase and such late apoptotic cells are presumed to exhibit distinct biological functions compared with early apoptotic cells, annexin V-positive but PI-negative cells. The immature DCs express little or no co-stimulatory molecules on their surface. Once activated, the DCs undergo a process of maturation, which is reflected by the increased expression of MHC, co-stimulatory molecules, and CD83 (Kim et al., 2006). Moreover, the capacity of antigen uptake and processing is lost in matured DCs but the ability of antigen presentation is increased. Apoptotic neutrophils express co-stimulatory molecules and CD83, which indicates that these cells are similar to the mature DC phenotype. However, it was reported that neutrophil functions such as phagocytic activity are downregulated in apoptotic cells (Whyte et al., 1993). We can speculate that the absence of costimulatory function in apoptotic neutrophils may be due to the variable expression of DC markers on these cells and the phenotypically different subset of apoptotic neutrophils display different cytokine profile for $T$ cell activation. Thus, it seems that apoptotic neutrophils expressing DC markers do not satisfy all criteria sufficiently to be regarded as APCs. Moreover, apoptotic neutrophils showing 
immature DC characteristics might function to suppress immune reactions because repetitive stimulation of naïve $T$ cells with immature DCs induces tolerance. More study will be needed to determine whether or not apoptotic neutrophils affect the $T$ cell functions if phagocytosis of apoptotic neutrophils does not occur.

Apoptosis is a prerequisite for the clearance of neutrophils by macrophages and for resolving inflammation (Savill, 1997). The innate immunity may be terminated after the phagocytosis of apoptotic neutrophils but apoptotic neutrophils might also contribute the development of adaptive immunity because bacteria and bacterial products in the inflammatory loci may be cross-presented by macrophages or DCs phagocytosing apoptotic neutrophils (van Gisbergen et al., 2005). It was reported that the uptake of apoptotic neutrophils by DCs leads to the enhanced expression of CD83 and $\mathrm{MHC}-\mathrm{II}$ on the DCs but a reduced capacity of DCs to stimulate mixed leukocyte reaction (Clayton et al., 2003). Positive staining of CD83 by an immunohistochemical assay in the inflammatory sites might involve both aged and apoptotic neutrophils (Iking-Konert et al., 2002). There was no evidence that neutrophils differentiate into DC-like cells in inflammation tissue until now. However, it is possible that apoptotic neutrophils in inflammatory loci may stain positively for the DC markers. Recently, it was reported that increased apoptosis accompanies the expression of DC markers in neutrophils in a pleural effusion from Mycobacterium tuberculosis patients (Aleman et al., 2005). Thus, it is possible that neutrophil apoptosis can affect the development of adaptive immunity by influencing the expression of various antigenpresenting molecules on their surface.

\section{Acknowledgement}

This paper was supported by the Dong-A University Research Fund in 2004.

\section{References}

Aleman M, de la Barrera SS, Schierloh PL, Alves L, Yokobori $\mathrm{N}$, Baldini M, Abbate E, Sasiain MC. In tuberculous pleural effusions, activated neutrophils undergo apoptosis and acquire a dendritic cell-like phenotype. J Infect Dis 2005; 192:399-409

Bliss SK, Butcher BA, Denkers EY. Rapid recruitment of neutrophils containing prestored IL-12 during microbial infection. J Immunol 2000;165:4515-21

Burg ND, Pillinger $\mathrm{MH}$. The neutrophil: function and regulation in innate and humoral immunity. Clin Immunol

\section{1;99:7-17}

Clayton AR, Prue RL, Harper L, Drayson MT, Savage CO. Dendritic cell uptake of human apoptotic and necrotic neutrophils inhibits CD40, CD80, and CD86 expression and reduces allogeneic $T$ cell responses: relevance to systemic vasculitis. Arthritis Rheum 2003;48:2362-74

de Carvalho Bittencourt M, Saas P, Fresnay S, Yerly-Motta V, Ferrand C, Perruche S, Duperrier A, Herve P, Tiberghien $P$, Chalmers DE. Exposure to exogenous DNA can modify the sensitivity of the Fas apoptotic pathway. J Gene Med 2002; 4:14-24

Dransfield I, Buckle AM, Savill JS, McDowall A, Haslett C, Hogg N. Neutrophil apoptosis is associated with a reduction in CD16 (FcyRIII) expression. J Immunol 1994;153:1254-63

Fanger NA, Liu C, Guyre PM, Wardwell K, O'Neil J, Guo TL, Christian TP, Mudzinski SP, Gosselin EJ. Activation of human T cells by major histocompatability complex class II expressing neutrophils: proliferation in the presence of superantigen, but not tetanus toxoid. Blood 1997;89:4128-35

Iking-Konert C, Cseko C, Wagner C, Stegmaier S, Andrassy K, Hansch GM. Transdifferentiation polymorphonuclear neutrophils: acquisition of CD83 and other functional characteristics of dendritic cells. J Mol Med 2001a;79:464-74

Iking-Konert C, Vogt S, Radsak M, Wagner C, Hansch GM, Andrassy K. Polymorphonuclear neutrophils in Wegener's granulomatosis acquire characteristics of antigen presenting cells. Kidney Int 2001b;60:2247-62

Iking-Konert C, Wagner C, Denefleh B, Hug F, Schneider M, Andrassy K, Hansch GM. Up-regulation of the dendritic cell marker CD83 on polymorphonuclear neutrophils (PMN): divergent expression in acute bacterial infections and chronic inflammatory disease. Clin Exp Immunol 2002;130: 501-8

Kim KD, Choi SC, Noh YW, Kim JW, Paik SG, Yang Y, Kim $\mathrm{K} 2 \mathrm{nd}$, Lim JS. Impaired responses of leukemic dendritic cells derived from a human myeloid cell line to LPS stimulation. Exp Mol Med 2006;38:72-84

Kobayashi SD, Voyich JM, Braughton KR, DeLeo FR. Down-regulation of proinflammatory capacity during apoptosis in human polymorphonuclear leukocytes. J Immunol 2003;170:3357-68

Kuchroo VK, Das MP, Brown JA, Ranger AM, Zamvil SS, Sobel RA, Weiner HL, Nabavi N, Glimcher LH. B7-1 and B7-2 costimulatory molecules activate differentially the Th1/Th2 developmental pathways: application to autoimmune disease therapy. Cell 1995;80:707-18

Lee MJ, Park JY, Lee SY, Lee JS, Jung DK, Bae YS, Kwak JY. Modulation of constitutive and delayed apoptosis by brefeldin A in human neutrophils. Int Immunopharmacol 2003;3:835-43

Lee SY, Oh JY, Lee MJ, Jang MJ, Park HY, Kim JW, Min DS, Park YM, Chang YC, Bae YS, Kwak JY. Anti-apoptotic mechanism and reduced expression of phospholipase $D$ in spontaneous and Fas-stimulated apoptosis of human neutrophils. Eur J Immunol 2004;34:2760-70

Mencacci A, Montagnoli C, Bacci A, Cenci E, Pitzurra L, 
Spreca A, Kopf M, Sharpe AH, Romani L. CD $80^{+} \mathrm{Gr}-1^{+}$ myeloid cells inhibit development of antifungal Th1 immunity in mice with candidiasis. J Immunol 2002;169:3180-90

Oehler L, Majdic O, Pickl WF, Stockl J, Riedl E, Drach J, Rappersberger K, Geissler K, Knapp W. Neutrophil granulocyte-committed cells can be driven to acquire dendritic cell characteristics. J Exp Med 1998;187:1019-28

Park HW, Park OJ, Shin JE, Choi YN. Receptor activator of $\mathrm{NF}-\kappa \mathrm{B}$ ligand enhances the activity of macrophages as antigen presenting cells. Exp Mol Med 2005;37:524-32

Park MA, Lee MJ, Lee SH, Jung DK, Kwak JY. Anti-apoptotic role of phospholipase $D$ in spontaneous and delayed apoptosis of human neutrophils. FEBS Lett 2002;519:45-9

Radsak M, lking-Konert C, Stegmaier S, Andrassy K, Hansch GM. Polymorphonuclear neutrophils as accessory cells for T-cell activation: major histocompatibility complex class II restricted antigen-dependent induction of T-cell proliferation. Immunology 2000;101:521-30

Randolph GJ, Beaulieu S, Lebecque S, Steinman RM, Muller WA. Differentiation of monocytes into dendritic cells in a model of transendothelial trafficking. Science 1998;282: 480-3

Savill J. Apoptosis in resolution of inflammation. J Leukoc Biol 1997;61:375-80

Sethna MP, van Parijs L, Sharpe AH, Abbas AK, Freeman GJ. A negative regulatory function of $B 7$ revealed in $B 7-1$ transgenic mice. Immunity 1994;1:415-21

Suzuki M, Shinohara F, Sato K, Taniguchi T, Takada H, Rikiishi $H$. Interleukin-1 $\beta$ converting enzyme subfamily inhibitors prevent induction of CD86 molecules by butyrate through a CREB-dependent mechanism in HL60 cells. Immunology 2003;108:375-83

Tateda K, Moore TA, Deng JC, Newstead MW, Zeng X, Matsukawa A, Swanson MS, Yamaguchi K, Standiford TJ. Early recruitment of neutrophils determines subsequent $\mathrm{T} 1 / \mathrm{T} 2$ host responses in a murine model of Legionella pneumophila pneumonia. J Immunol 2001;166:3355-61

Taub DD, Anver M, Oppenheim JJ, Longo DL, Murphy WJ. T lymphocyte recruitment by interleukin-8 (IL-8). IL-8induced degranulation of neutrophils releases potent chemoattractants for human T lymphocytes both in vitro and in vivo. J Clin Invest 1996;97:1931-41 van Gisbergen KP, Geijtenbeek TB, van Kooyk Y. Close encounters of neutrophils and DCs. Trends Immunol 2005; 26:626-31

Vella A, Sartoris S, Bambara L, Ortolani R, Carletto A, Biasi D, Stefani E, Tridente G. Cell contact-dependent PMN HLA-DR and CD69 membrane expression induced by autologous mono-lymphocytes and cell lines. Inflammation 2002;26:143-52

Ward C, Chilvers ER, Lawson MF, Pryde JG, Fujihara S, Farrow SN, Haslett C, Rossi AG. NF- $\mathrm{kB}$ activation is a critical regulator of human granulocyte apoptosis in vitro. J Biol Chem 1999a;274:4309-18

Ward C, Dransfield L, Chilvers ER, Haslett I, Rossi AG. Pharmacological manipulation of granulocyte apoptosis: potential therapeutic targets. Trends Pharmacol Sci 1999b; 20:503-9

Watson RW, Rotstein OD, Jimenez M, Parodo J, Marshall JC. Augmented intracellular glutathione inhibits Fas-triggered apoptosis of activated human neutrophils. Blood 1997;89: 4175-81

Watson RW, O'Neill A, Brannigen AE, Coffey R, Marshall JC, Brady HR, Fitzpatrick JM. Regulation of Fas antibody induced neutrophil apoptosis is both caspase and mitochondrial dependent. FEBS Lett 1999;453:67-71

Whyte MKB, Meagher LC, MacDermot J, Haslett C. Impairment of function in aging neutrophils is associated with apoptosis. J Immunol 1993;150:5124-34

Windhagen A, Maniak S, Gebert A, Ferger L, Wurster U, Heidenreich F. Human polymorphonuclear neutrophils express a B7-1-like molecule. J Leukoc Biol 1999;66:945-52

Yamashiro S, Wang JM, Yang D, Gong WH, Kamohara $\mathrm{H}$, Yoshimura T. Expression of CCR6 and CD83 by cytokine-activated human neutrophils. Blood 2000;96:3958-63

Yoshimura S, Bondeson J, Foxwell BM, Brennan FM, Feldmann M. Effective antigen presentation by dendritic cells is NF- $\mathrm{NB}$ dependent: coordinate regulation of MHC, co-stimulatory molecules and cytokines. Int Immunol 2001; 13:675-83

Zhao J, Freeman GJ, Gray GS, Nadler LM, Glimcher LH. A cell type-specific enhancer in the human B7.1 gene regulated by NF-кB. J Exp Med 1996;183:777-89 